\title{
A Common Risk Classification Concept for Safety Related Gas Leaks and Fugitive Emissions?
}

\author{
Torgrim Log $1,2,3, * \mathbb{D}$ and Wegar Bjerkeli Pedersen ${ }^{3,4} \mathbb{D}$ \\ 1 Department of Fire Safety and HSE Eng., Fire Disaster Research Group, Western Norway University of \\ Applied Sciences, 5545 Haugesund, Norway \\ 2 Equinor Kårstø, 5565 Kårstø, Norway \\ 3 Equinor Hammerfest, 9601 Hammerfest, Norway; wpe@equinor.com \\ 4 Department of Engineering and Safety, The Arctic University of Norway, 9019 Tromsø, Norway \\ * Correspondence: torgrim.log@hvl.no; Tel.: +47-900-50001
}

Received: 9 September 2019; Accepted: 22 October 2019; Published: 24 October 2019

check for updates

\begin{abstract}
Gas leaks in the oil and gas industry represent a safety risk as they, if ignited, may result in severe fires and/or explosions. Unignited, they have environmental impacts. This is particularly the case for methane leaks due to a significant Global Warming Potential (GWP). Since gas leak rates may span several orders of magnitude, that is, from leaks associated with potential major accidents to fugitive emissions on the order of $10^{-6} \mathrm{~kg} / \mathrm{s}$, it has been difficult to organize the leaks in an all-inclusive leak categorization model. The motivation for the present study was to develop a simple logarithmic table based on an existing consequence matrix for safety related incidents extended to include non-safety related fugitive emissions. An evaluation sheet was also developed as a guide for immediate risk evaluations when new leaks are identified. The leak rate table and evaluation guide were tested in the field at five land-based oil and gas facilities during Optical Gas Inspection (OGI) campaigns. It is demonstrated how the suggested concept can be used for presenting and analysing detected leaks to assist in Leak Detection and Repair (LDAR) programs. The novel categorization table was proven valuable in prioritizing repair of "super-emitter" components rather than the numerous minor fugitive emissions detected by OGI cameras, which contribute little to the accumulated emissions. The study was limited to five land based oil and gas facilities in Norway. However, as the results regarding leak rate distribution and "super-emitter" contributions mirror studies from other regions, the methodology should be generally applicable. To emphasize environmental impact, it is suggested to include leaking gas GWP in future research on the categorization model, that is, not base prioritization solely on leak rates. Research on OGI campaign frequency is recommended since frequent coarse campaigns may give an improved cost benefit ratio.
\end{abstract}

Keywords: fugitive emissions; hydrocarbon leaks; optical Gas Imaging (OGI); leak detection and repair (LDAR)

\section{Introduction}

Natural gas is currently the third largest source of energy, covering about $20 \%$ of the world's primary energy demand. Unlike other fossil fuels, the global demand of natural gas is expected to increase over the next few decades. In the International Environment Agency (IEA) Sustainable Development Scenario in the World Energy Outlook 2018, designed to be fully aligned with the Paris Agreement goal of keeping the global average temperature rise below $2{ }^{\circ} \mathrm{C}$, natural gas is expected to supply one quarter of the world's primary energy demand by 2040 [1]. The increasing demand is driven by the development in Asia, governmental policies of carbon-taxing and coal-to-gas switch in industries and buildings. The increasing supply is primarily met by the US shale gas revolution. 
Methane is the most prominent gas in natural gas mixtures. During processing, the natural gas is dried, $\mathrm{CO}_{2}$ and traces of inorganic materials-for example, sulphur and mercury-are removed as required by the customer specifications. Wet gas and rich gas are typically separated from the oil before the gas is treated in a gas processing facility. The wet gas or NGL (Natural Gas Liquids), contains a mixture of heavier gases (ethane, propane, butanes and naphtha), which may be further separated to produce clean gas components or gas mixtures of varying properties. Rich gas has a lower content of ethane and other heavier hydrocarbons. Dry gas consists mainly of methane with some ethane and only minor fractions of heavier hydrocarbons. In some facilities, gas containing only methane and some ethane is compressed and cooled to LNG (liquefied natural gas), while in other facilities the gas is used to produce other products, for example, methanol.

Natural gas and in particular its primary gas component methane, represents the lowest emitting fossil fuel when combusted. Natural gas therefore has many environmental advantages over coal and oil. The flexibility provided by the natural gas when converted to LNG also makes the transition to less $\mathrm{CO}_{2}$ release from the energy consumers easier. It may therefore be concluded that natural gas will play a major role in the global energy transition towards a low-carbon future.

In all engineered systems, there is unfortunately a loss of energy. In for example, the electrical power grid system, $5 \%$ of the transmitted power is typically lost [2]. Processing and transporting natural gas, as well as compression and cooling of natural gas to produce LNG, require operations at high pressures. Transport pipelines may operate at pressures above 100 bar while production of LNG prior to cooling typically involves pressures in the range of 20-60 bar. Leaks therefore occur both in the processing and transport of gas to the markets. Unfortunately, methane is a potent greenhouse gas (GHG) with a global warming potential (GWP) of 28-36 times $\mathrm{CO}_{2}$ in a 100-year time frame. Having both a shorter atmospheric lifetime and higher energy absorption potential than $\mathrm{CO}_{2}$, methane's short-term global GWP is estimated to 84-87 [3,4]. The way the greenhouse gas emissions are assessed is not straight forward, as many factors are part of the picture [5,6]. It is, however, clear that uncontrolled methane leaks and emissions along the natural gas value chain may drastically reduce the climate benefits of natural gas over other fossil fuels, especially in the short term.

When studying fugitive emissions from the UK high-pressure pipeline transport system, that is, up to 85 bar pressure, Boothroyd et al. [7] detected both soil and air emissions. They concluded that the loss to the air accumulated to as much as 627 tonnes $\mathrm{CH}_{4} / \mathrm{km} / \mathrm{yr}\left(241-1123\right.$ tonnes $\mathrm{CH}_{4} / \mathrm{km} / \mathrm{yr}$ interquartile range). The estimated natural gas loss to the soil was $62.6 \mathrm{kt} / \mathrm{year}$. For one particular pipeline, the average distance between leaks indicated that nearly all pipe welding joints were leaking. By investigating the Bangladesh Titas Gas distribution network by means of soap screening and a Gasurveyor 500 series instrument (Gas Measurement Instruments Ltd, Renfrew, Scotland, UK), Mandal and Morshed [8] found several leak sources. Scrubber dump valves and pressure relief valves were identified as the most severe leak sources with respectively average leak rates of $217 \mathrm{~L} / \mathrm{min}$ and $438 \mathrm{~L} / \mathrm{min}$. Average leak rates of respectively 4.0, 8.0 and $1.6 \mathrm{~L} / \mathrm{min}$ were found for insulation points, tube fittings and connectors. These examples indicate that the methane losses may be significant and may thereby reduce the environmental benefit of natural gas as a fuel compared to more carbon rich fuels.

According to Miller and Michalak [9], the current emission measurement and estimation methodologies are associated with high degrees of uncertainty. Results from top-down (e.g., remote atmospheric measurements) and bottom-up (e.g., direct component measurements) studies show significant differences and much research on this topic is initiated by environmental agencies and oil and gas operator consortiums. According to the IEA, the methane emissions must be lower than 3\% for natural gas to represent a cleaner energy provider in the short-term than coal [10]. The general consensus is, however, that the global methane losses along the value chain are lower than $3 \%$. Recent studies estimate that the methane emission from US oil and gas supply chain is close to $2.3 \%$ of the gross US gas production [11]. 
National environmental protection agencies (EPAs) are increasingly concerned about the accumulated leak rates in the oil and gas industry. In several countries, for example, Norway and USA, the EPAs want to quantify the leak rates as a basis for issuing environmental taxes. There are indications of methane leak rates being higher than the respective EPAs estimates [12,13]. Loss of methane gas to the atmosphere must be prevented as these losses counteract an improvement in GWP relative to carbon rich fuels.

Leak rates and greenhouse gas (GHG) footprint of both the Norwegian LNG and pipeline gas exported to Europe have been found to be well below recently reported EU averages [14]. The estimated $\mathrm{CH}_{4}$ emissions were $0.01-0.04 \%$ of the production rate. But there are leaks and the Norwegian Environmental Agency (NEA) requires Differential Absorption Lidar (DIAL) recordings, which is also frequently used to record methane gas emissions from industry areas [15] and landfills [16]. In some special cases, the DIAL technique can also be used to record leaks from for example, large process units and storage tanks. However, to search for leaks on a component level, close-up methods are required.

It is well known internationally that a minor fraction of the emission sources dominates the accumulated methane emissions $[3,17]$. Rather than searching for numerous marginal small leaks on the order of $1 \times 10^{-6} \mathrm{~kg} / \mathrm{s}$, to start looking for the "super-emitters" may be worthwhile. If the average period a few "super-emitters" are active is half a year, that is, before detected in a yearly OGI campaign, they may dominate the accumulated leak rate. Searching more frequently for "super-emitters and not devote so much time to the marginal leaks, could be very beneficial with respect to environmental impacts, safety and plant economy.

Methods that can be used near the leak sources may reveal exactly where the leaks occur and which leaks contribute most to the accumulated emissions, making it easier to prioritize repair of the "super-emitters" [3,17]. On the component level, since such "super-emitters" may emit orders of magnitude more gas than minor fugitive emissions, one may question whether a high accuracy is necessary, that is, over-engineering may be an issue [3]. Since the "super-emitters" contribute so much to the accumulated leak rates, it is important to locate and repair these.

In the present study, we have developed and tested a concept for improving the focus on the leaks contributing most to the accumulated emissions. An incident consequence matrix used by the Petroleum Safety Authority of Norway, as well as oil and gas companies operating on- and offshore in Norwegian territories, has been extended and tested as a tool also for categorizing fugitive emissions. It was also tested for communicating the importance of addressing "super-emitters" with less focus on a high number of minor leaks significantly smaller than these "super-emitters." A leak risk evaluation guide is presented and a discussion regarding too high focus on quantifying all detected leaks, rather than focusing on the major contributors, is included. Some comments are included regarding safety risk versus fugitive emissions and possible benefits of a common gas leak categorization system. The novelty of the paper is the concept presented and the way it can be implemented by operators and managers.

\section{Gas Leak Detection in Processing Facilities}

\subsection{Fire Safety Related Properties of Natural Gas}

Natural gas typically consists of $90-95$ vol\% methane $\left(\mathrm{CH}_{4}\right), 3-6$ vol\% ethane $\left(\mathrm{C}_{2} \mathrm{H}_{6}\right)$, with some minor amounts of longer chain alkanes, for example, propane $\left(\mathrm{C}_{3} \mathrm{H}_{8}\right)$, butane $\left(\mathrm{C}_{4} \mathrm{H}_{10}\right)$ and so forth, as well as varying amounts of $\mathrm{N}_{2}, \mathrm{CO}_{2}$ and $\mathrm{H}_{2} \mathrm{~S}$, which is generally removed when processing the gas. The molar mass of methane and ethane are $16.04 \mathrm{~g} / \mathrm{mol}$ and $30.07 \mathrm{~g} / \mathrm{mol}$, respectively. A representative molar mass for natural gas may typically be $19 \mathrm{~g} / \mathrm{mol}$, while dry air has molar mass $28.97 \mathrm{~g} / \mathrm{mol}$. At $20^{\circ} \mathrm{C}$, the density of natural gas is about $0.79 \mathrm{~kg} / \mathrm{m}^{3}$ while the density of air is $1.21 \mathrm{~kg} / \mathrm{m}^{3}$. Unless very cold due to the expansion from a high-pressure source, that is, the Joule Thompson effect or resulting from for example, an evaporating LNG leak, a gas leak will be lighter than the ambient air. 
Natural gas is flammable, with a heat of combustion of about $50 \mathrm{~kJ} / \mathrm{g}$. It has a minimum ignition energy (MIE) of $0.25 \mathrm{~mJ}$, that is, it is easily ignited when mixed with air. The lower flammability limit in air, which is also denoted as the lower explosion limit (LEL), is $5 \mathrm{vol} \%$ and the upper flammability limit of $15 \mathrm{vol} \%$ [18].

Due to the high pressures associated with natural gas processing and pipeline transport, even small leak openings may give substantial leak rates. Ignited large leaks have given many major accidents worldwide. Early detection of gas leaks is therefore given high priority to prevent fires and/or explosions.

\subsection{Fixed Gas Detectors for Safety Related Leak Detection}

Gas processing plants, compression facilities for gas transport and LNG plants are equipped with fixed gas detectors to detect safety related leaks. These gas detectors usually come in two principle categories, that is, point detectors and line-of-sight detectors. There are many different types of point gas detectors. Previously, combustion-based gas detectors were used. These detectors relied on recording the oxidation of gas on a heated catalyst and had quite long response times. Today, infra-red (IR) light absorption detectors dominate, at least in Norwegian on- and offshore facilities. These are based on recording the IR absorption of the $\mathrm{C}-\mathrm{H}$ bonds in the gas at about $3.4 \mu \mathrm{m}$ wavelength. Readings from point detectors are usually reported in \% LEL. For new equipment, the detection limit for high alarm $(\mathrm{H})$ is typically 10\% LEL with high-high alarm $(\mathrm{HH})$ at $20 \%$ LEL. Line of sight detectors work similarly, however with a sender and a receiver, where any absorption of wavelengths corresponding to the C-H bond IR signature between these, is recorded. Line of sight detectors typically report the values in LELm (LEL meter), with set values for $\mathrm{H}$ alarm and $\mathrm{HH}$ alarm typically at 1 LELm and 2 LELm, respectively. At $\mathrm{H}$ alarm, the plant operators are warned and non-essential electrical equipment is automatically disengaged. Even stronger actions are taken at $\mathrm{HH}$ alarm or when more than one gas detector $\mathrm{H}$ alarm is activated.

\subsection{Investigation of Gas Release Incidents}

In a number of cases in the world-wide oil and gas industry, large gas releases have been ignited and thereby caused major accidents. Containment is therefore generally accepted as the most important barrier against severe incidents. Diluting gas leaks to below the LEL is also a possible safety measure. In other industries, such as the coal mining, where methane is continually released, ventilation is critical for ensuring safe conditions [19].

Major oil and gas companies relentlessly investigate situations that have resulted in safety related gas leaks, regardless of the release being ignited or not. Investigation of such leak incidents is indeed required by the Norwegian regulations, stating that "Situations that occur frequently or that have great actual or potential consequences, shall be investigated" [20]. The motivation for investigating gas leaks is to learn from the incidents and enable the companies to prevent future accidents and near misses.

Since loss of containment is a severe risk, most companies have developed criteria for leak severity categorization represented by the leak rate for lasting leaks and accumulated leak for brief leak bursts. A representative general incident and near miss consequence matrix is presented in Figure 1, where also other incidents such as for example, personnel injury, uncontrolled discharge/emissions to the environment and loss of reputation are included. In Norway, such matrixes have been used for more than three decades, with only minor adjustments. For flammable oil and gas leaks, the consequence matrix is organized from the most severe to the less severe leak rates in the following order: leak rate $>$ $10 \mathrm{~kg} / \mathrm{s} \rightarrow \operatorname{Red} 1 ; 10 \mathrm{~kg} / \mathrm{s}>$ leak rate $>1 \mathrm{~kg} / \mathrm{s} \rightarrow \operatorname{Red} 2 ; 1 \mathrm{~kg} / \mathrm{s}>$ leak rate $>0.1 \mathrm{~kg} / \mathrm{s} \rightarrow$ Yellow 3; leak rate $<0.1 \mathrm{~kg} / \mathrm{s} \rightarrow$ Green 4 ; leak rate $<<0.1 \mathrm{~kg} / \mathrm{s} \rightarrow$ Green 5 . It is interesting to notice that the leak rate categories are organized logarithmically based of the leak rates, both for actual leaks and for potential consequences under slightly altered circumstances. 


\begin{tabular}{|c|c|c|c|c|c|c|c|c|c|c|c|c|c|c|}
\hline \multirow{2}{*}{$\begin{array}{c}\text { Degree } \\
\text { of } \\
\text { serious- } \\
\text { ness }\end{array}$} & \multicolumn{2}{|c|}{ Injury } & \multicolumn{2}{|c|}{$\begin{array}{c}\text { Work related illness } \\
\text { (WRI) }\end{array}$} & \multicolumn{2}{|c|}{$\begin{array}{c}\text { Uncontrolled } \\
\text { discharge/emissions }\end{array}$} & \multicolumn{2}{|c|}{$\begin{array}{c}\text { Oil-/gas/flammable } \\
\text { liquids leakages }\end{array}$} & \multicolumn{2}{|c|}{ Fire/explosion } & \multicolumn{2}{|c|}{$\begin{array}{c}\text { Failure in } \\
\text { safety/security } \\
\text { functions and } \\
\text { barriers }\end{array}$} & \multicolumn{2}{|c|}{ Reputation } \\
\hline & Actual & Potent. & Actual & Potent. & Actual & Potent. & Actual & Potent. & Actual & Potent. & Actual & Potent. & Actual & Potent. \\
\hline 1 & \multicolumn{2}{|c|}{ Fatality } & \multicolumn{2}{|c|}{$\begin{array}{l}\text { Work related illness } \\
\text { that result in death }\end{array}$} & \multicolumn{2}{|c|}{\begin{tabular}{|c|}
$\begin{array}{c}\text { Single spill with long } \\
\text { term effect on the } \\
\text { environment. }\end{array}$ \\
$\begin{array}{c}\text { Release to air > yearly } \\
\text { expected emission of } \\
\text { component }\end{array}$ \\
\end{tabular}} & \multicolumn{2}{|c|}{$\begin{array}{l}>10 \mathrm{~kg} / \mathrm{s} \\
\begin{array}{c}\text { or brief leakages } \\
>100 \mathrm{~kg}\end{array}\end{array}$} & \multicolumn{2}{|c|}{$\begin{array}{l}\text { Whole facility/plant } \\
\text { exposed }\end{array}$} & \multicolumn{2}{|c|}{$\begin{array}{c}\text { Threaten whole } \\
\text { facility/plant }\end{array}$} & \multicolumn{2}{|c|}{$\begin{array}{l}\text { Great international } \\
\text { negativ exposure in } \\
\text { mass media and } \\
\text { among organisations }\end{array}$} \\
\hline 2 & \multicolumn{2}{|c|}{$\begin{array}{c}\text { Serious lost time } \\
\text { injury/serious injury }\end{array}$} & \multicolumn{2}{|c|}{$\begin{array}{c}\text { Serious work related } \\
\text { illness }\end{array}$} & \multicolumn{2}{|c|}{$\begin{array}{c}\text { Single spill with } \\
\text { medium term effect on } \\
\text { the environment. } \\
\text { Release to air > } \\
\text { monthly expected } \\
\text { emission of } \\
\text { component }\end{array}$} & \multicolumn{2}{|c|}{ 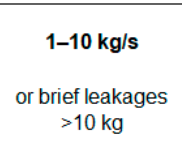 } & $\begin{array}{r}\text { Large } \\
\text { facility/ple }\end{array}$ & $\begin{array}{l}\text { art of } \\
t \text { exposed }\end{array}$ & \multicolumn{2}{|c|}{$\begin{array}{c}\text { Threaten large part of } \\
\text { facility/plant }\end{array}$} & \multicolumn{2}{|c|}{$\begin{array}{l}\text { Medium international } \\
\text { negative exposure in } \\
\text { mass media and } \\
\text { among organisations }\end{array}$} \\
\hline 3 & \multicolumn{2}{|c|}{$\begin{array}{l}\text { Other lost time injury } \\
\text { or Injury involving } \\
\text { substitute work }\end{array}$} & \multicolumn{2}{|c|}{$\begin{array}{c}\text { Work related illness } \\
\text { that results in short- } \\
\text { term absence or } \\
\text { restricted/ alternative } \\
\text { work }\end{array}$} & \multicolumn{2}{|c|}{\begin{tabular}{|c|} 
Single spill with short \\
term effect on the \\
environment. \\
Release to air > \\
weekly expected \\
emission of \\
component
\end{tabular}} & \multicolumn{2}{|c|}{$\begin{array}{c}0.1-1 \mathrm{~kg} / \mathrm{s} \\
\text { or brief leakages } \\
>1 \mathrm{~kg}\end{array}$} & $\begin{array}{r}\text { Parts of } f_{f} \\
\text { exp }\end{array}$ & $\begin{array}{l}\text { ility/plant } \\
\text { sed }\end{array}$ & \multicolumn{2}{|c|}{$\begin{array}{l}\text { Threaten parts of } \\
\text { facility/plant }\end{array}$} & \multicolumn{2}{|c|}{$\begin{array}{c}\text { National negative } \\
\text { exposure in mass } \\
\text { media, from } \\
\text { authorities on national } \\
\text { level }\end{array}$} \\
\hline 4 & \multicolumn{2}{|c|}{$\begin{array}{l}\text { Medical treatment } \\
\text { injury }\end{array}$} & \multicolumn{2}{|c|}{$\begin{array}{c}\text { Work related illness } \\
\text { that results in } \\
\text { treatment from } \\
\text { authorised health care } \\
\text { personnel }\end{array}$} & \multicolumn{2}{|c|}{\begin{tabular}{|c|} 
Single spill with minor \\
effect on the \\
environment. \\
Release to air < \\
weekly expected \\
emission of \\
component \\
\end{tabular}} & \multicolumn{2}{|c|}{$<0.1 \mathrm{~kg} / \mathrm{s}$} & $\begin{array}{r}\text { Local } \\
\text { facility/pl }\end{array}$ & $\begin{array}{l}\text { rea of } \\
\text { texposed }\end{array}$ & \multicolumn{2}{|c|}{ Threaten local area } & \multicolumn{2}{|c|}{$\begin{array}{c}\text { Local/regional } \\
\text { negative exposure in } \\
\text { mass media, from } \\
\text { authorities and } \\
\text { customers }\end{array}$} \\
\hline 5 & \multicolumn{2}{|c|}{ First aid injury } & \multicolumn{2}{|c|}{$\begin{array}{l}\text { Other work related } \\
\text { illnesses }\end{array}$} & \multicolumn{2}{|c|}{$\begin{array}{l}\text { Single spill or release } \\
\text { to air with negligible } \\
\text { effect on the } \\
\text { environment }\end{array}$} & \multicolumn{2}{|c|}{$\begin{array}{l}\quad<<0.1 \mathrm{~kg} / \mathrm{s} \\
\text { (significantly less } \\
\text { than } 0.1 \mathrm{~kg} / \mathrm{s} \text { ) }\end{array}$} & \multicolumn{2}{|c|}{$\begin{array}{l}\text { Negligible risk for } \\
\text { facility/plant }\end{array}$} & $\begin{array}{r}\text { Negligi } \\
\text { facili }\end{array}$ & $\begin{array}{l}\text { risk for } \\
\text { plant }\end{array}$ & $\begin{array}{r}\text { Limitec } \\
\text { persons } \\
\text { cus }\end{array}$ & $\begin{array}{l}\text { o a few } \\
\text { a single } \\
\text { ner }\end{array}$ \\
\hline
\end{tabular}

Figure 1. Representative consequence matrix for incidents and near misses in the Norwegian oil and gas industry.

\subsection{Previous Detection of Fugitive Emissions from Production Facilities}

In recent years, campaigns for detecting methane leaks at land-based hydrocarbon processing facilities in Norway were mostly based on the Differential Absorption Lidar (DIAL) technique, since that method was considered as best available technology (BAT). Leak detection programs were mandatory and enforced by the NEA due to the methane greenhouse gas potential. Leak rates recorded by third-parties were used to issue taxes. The measurements were typically performed by a DIAL truck visiting the site $[15,16]$ to record methane gas in the atmosphere upwind and downwind of the facility. Usually, the truck had to be positioned within the "hot plant," that is, where there should be no ignition sources. As a non-Ex safe unit, there was a need for work permits for this operation. The truck was at each site for 2-3 weeks and the recordings could be severely affected by surrounding nature, for example, mire habitats releasing methane at changing rates when for example, heated by sun radiation. Only in a few cases, the DIAL technique could reveal which equipment was indeed leaking. Besides these issues, the DIAL technology can get a fair representation of the total fugitive emissions, however, generally without providing details about any individual "super-emitters."

For single leak identification, close-up methods are required. Until recently, the preferred solution at Norwegian facilities was sniffing with handheld gas detectors held $10 \mathrm{~cm}$ from potential leak sources and the readings were either in ppm (parts per million) or in \%LEL. The measurements at $10 \mathrm{~cm}$ distance were done on a regular basis, for example, weekly, as detection at this distance was recognized as important for detecting safety related leaks. Measurement campaigns using $1 \mathrm{~cm}$ distance were done less frequently, for example, once a year, to detect the smallest fugitive emissions.

\subsection{Detecting Minor Gas Leaks and Seepages}

Unless directly exposing a point gas detector, a natural gas seepage of for example, $5 \mathrm{~cm}^{3} / \mathrm{s}$ $\left(3.5 \times 10^{-6} \mathrm{~kg} / \mathrm{s}, 125 \mathrm{~kg} / \mathrm{y}\right)$ will not result in a $\mathrm{H}$ alarm of neither point gas detectors nor line-of-sight gas detectors. The released gas will be too diluted to result in alarm activation. Such small leak rates in an open area or in an indoor ventilated area, do not represent a safety issue. However, when undetected by the fixed gas detectors, these leaks may release gas for several years. When accumulating the 
contribution from numerous non-safety related leaks, it is apparent that they contribute to a significant environmental impact, as well as a loss of valuable products.

Handheld infrared (IR) based optical gas imaging (OGI) cameras have now been introduced for leak detection. Ravikumar et al. [21] recently investigated whether the OGI technology could represent an effective method for methane leak detection. This was done based on the U.S. EPA proposed regulations requiring use of OGI passive IR technologies in LDAR programs. It was concluded that $80 \%$ of the emissions could be detected at $10 \mathrm{~m}$ distance. This work was followed up with a study where an OGI camera was used for blind tests at mock-ups resembling flange leaks [17]. At $6 \mathrm{~m}$ imaging distance, a 50\% likelihood detection limit was about $20 \mathrm{~g} \mathrm{CH}_{4} / \mathrm{h}(0.0056 \mathrm{~g} / \mathrm{s})$, corresponding to a volumetric rate of $7.0 \mathrm{~cm}^{3} / \mathrm{s}$. The $90 \%$ detection likelihood limit followed a power-law relationship with distance.

There are several benefits when being able to walk into the field and visually see gas leaks. One can see exactly which point the leak originates as well as getting an estimate of the leak rate by the gas plume character. In a recent OGI study, several methane leaks of about $1 \mathrm{~cm}^{3} / \mathrm{s}(0.0008 \mathrm{~g} / \mathrm{s})$ were identified in an LNG plant [22].

\subsection{Leak Rate Quantification}

Leak rates may be estimated by a variety of methods. Test campaigns have been performed at Total's Lacq Platform in France using gas spectral imaging systems, that is, multispectral Long-Wavelength

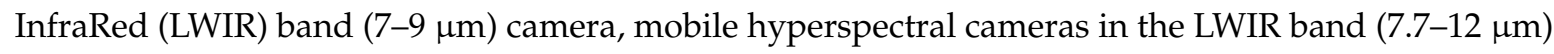
and Light Detection and Ranging (LIDAR) multi gas system. Teams from France, Spain, USA and Norway were invited to assess remote-sensing systems for methane leak quantification [23]. The testing showed that methane leaks in the range from $0.7 \mathrm{~g} / \mathrm{s}$ to $140 \mathrm{~g} / \mathrm{s}$ could be visualized and quantified in real time using mobile Telops Hyper-Cam, while also confirming the performance of several remote sensing technologies. Open path laser systems have been used [24] for gas leak detection at rates of about $1 \mathrm{~L} / \mathrm{min}$. Low-cost, off-the-shelf, metal oxide-based methane $\left(\mathrm{CH}_{4}\right)$ gas sensors have also been tested for monitoring methane leaks. They gave quite reliable data in laboratory conditions when properly correcting for the influence of air temperature and relative humidity [25], as well as in the field for recording ambient concentrations [26]. Dyakowska and Pegielska [27] tested trained operators using the EN 15446 and the Hi Flow sampler technique and found that the Hi Flow sampler gave the best results. By carefully following the measurement procedures, the best operator was able to quantify the leak rates to within $3.5 \%$ in blind tests.

For an LDAR program, it may however not be necessary to identify leak rates to within this accuracy, that is, when the main goal is to prioritize leaks for repair to reduce emissions. As identified leak rates are of varying orders of magnitude, a less refined mesh may be sufficient for identifying the "super-emitters," which, according to Brandt et al. [3] should be focused.

In the present study, OGI cameras were used for identifying leaks. For quick estimates of leak rate, a very simple guide was developed to support the operators in doing soap bubble tests using spray (CRC Leak Finder Spray). The guide, as shown in Figure 2, presents the volume of a sphere as a function of diameter to assist in volume rate estimates of the bubbles generated by leaks. The operators were instructed to count to for example, $10 \mathrm{~s}(1001,1002,1003, \ldots)$, record the dimension of the individual bubbles or bubble groups, using a ruler, note the total bubble volume, correct for the shape of the bubbles (e.g., half sphere) and divide by the bubble development time. This gives a fair leak rate estimate in $\mathrm{cm}^{3} / \mathrm{s}$. Blind tests were also conducted in a lab, where $90 \%$ of the estimates were within $\pm 30 \%$ of the correct value. In the field it may be expected that volume estimates are slightly less accurate. Leaks that generate bubbles so fast that the operators were unable to quantify these leaks were simply identified as "super-emitters." Such leaks could then, if needed and considered safe, be quantified by for example, Hi Flow sampling. 

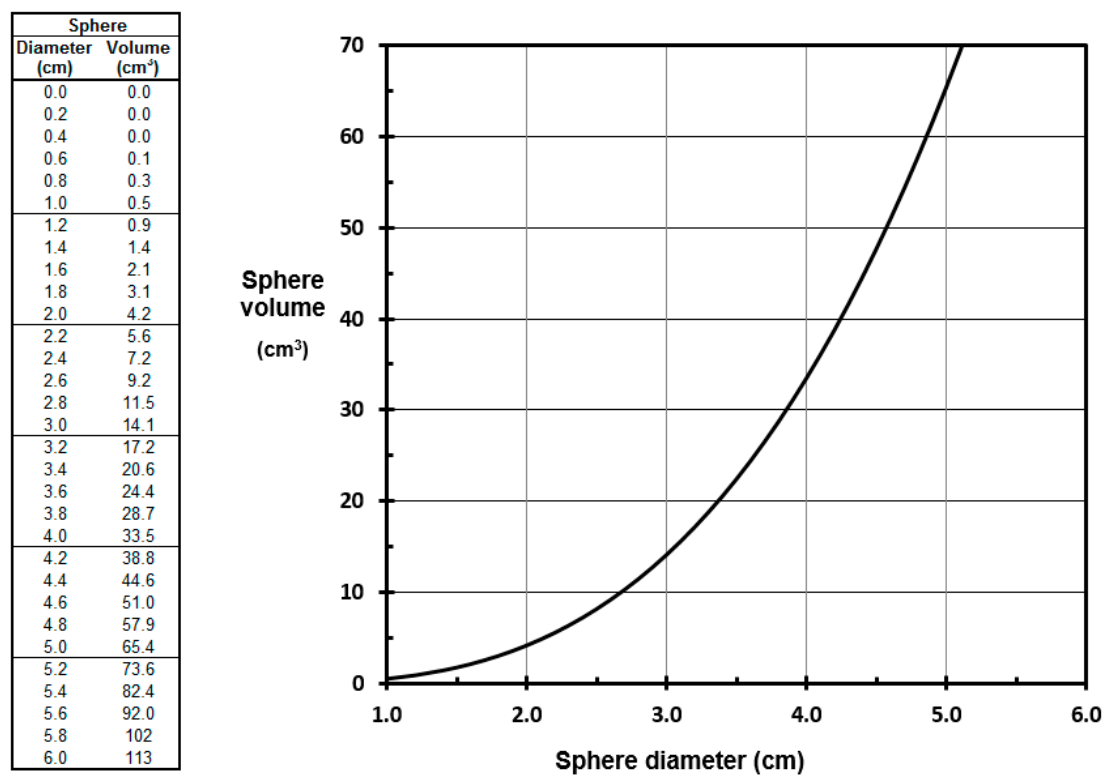

Figure 2. Guide for estimating volume rate of minor gas leaks.

\section{Proposed Leak Categorization Concept and Risk Evaluation Guide}

\subsection{Leak Categorization Concept}

All gas leaks represent environmental challenges, while in outdoor conditions, the smallest leaks do not represent a safety risk, that is, fire or explosion risk. Since all leaks are relevant to the environment, it would be beneficial to have a common consequence classification concept, that is, ranging from more than $10 \mathrm{~kg} / \mathrm{s}$ to less than for example, $10^{-6} \mathrm{~kg} / \mathrm{s}$. This span would include release rates associated with potential major accidents and the smallest detectable fugitive emissions. Assuming natural gas, that is, with at a density not that much short of $1 \mathrm{~kg} / \mathrm{m}^{3}$, a leak rate of $10^{-6} \mathrm{~kg} / \mathrm{s}$ corresponds to a volume rate of about $1 \mathrm{~cm}^{3} / \mathrm{s}$ at ambient conditions. In open areas, this leak rate obviously does not represent a significant safety risk. A leak rate three orders of magnitude larger $\left(10^{-3} \mathrm{~kg} / \mathrm{s}\right.$, that is, about $1.0 \mathrm{~L} / \mathrm{s}$, corresponding to a heat release rate of $50 \mathrm{~kW}$ if ignited) may, however, be considered a safety related leak, at least when it comes to potential personnel exposure. To be somewhat conservative, one may define all leaks $>10^{-4} \mathrm{~kg} / \mathrm{s}$ as safety related leaks when considering for example, burns risk for field operators.

With leak rates spanning several orders of magnitude, the logarithmic based safety related incident categorization matrix, which is familiar to managers and operators in Norway, represents an interesting concept. By extending it to smaller leak rates, fugitive emissions may then be included. It may be discussed where the cut between the safety related leaks and purely environmental risk should be drawn. In the suggested categorization table, a new category "Green 6," that is, with leak rates in the range $1 \times 10^{-4}-1 \times 10^{-3} \mathrm{~kg} / \mathrm{s}$, is introduced and the cut between the safety related risk and purely environmental risk is proposed at $1 \times 10^{-4} \mathrm{~kg} / \mathrm{s}$, as indicated in Figure 3 .

\begin{tabular}{|c|c|c|c|c|c|c|c|c|c|}
\hline & \multicolumn{6}{|c|}{ Safety related leaks } & \multicolumn{3}{|c|}{ Fugitive emissions } \\
\hline & Red & Red & Yellow & Green & Green & Green & & & \\
\hline Level: & 1 & 2 & 3 & 4 & 5 & 6 & 7 & 8 & $g$ \\
\hline Mass rate: & $>10 \mathrm{~kg} / \mathrm{s}$ & $<10 \mathrm{~kg} / \mathrm{s}$ & $<1.0 \mathrm{~kg} / \mathrm{s}$ & $<0.1 \mathrm{~kg} / \mathrm{s}$ & $<10^{-2} \mathrm{~kg} / \mathrm{s}$ & $<10^{-3} \mathrm{~kg} / \mathrm{s}$ & $<10^{-4} \mathrm{~kg} / \mathrm{s}$ & $<10^{-5} \mathrm{~kg} / \mathrm{s}$ & $<10^{-6} \mathrm{~kg} / \mathrm{s}$ \\
\hline Vol. rate: & $>10 \mathrm{~m}^{3} / \mathrm{s}$ & $<10 \mathrm{~m}^{3} / \mathrm{s}$ & $<1.0 \mathrm{~m}^{3} / \mathrm{s}$ & $<0.1 \mathrm{~m}^{3} / \mathrm{s}$ & $<10 \mathrm{~L} / \mathrm{s}$ & $<1.0 \mathrm{~L} / \mathrm{s}$ & $<0.1 \mathrm{~L} / \mathrm{s}$ & $<10 \mathrm{~cm}^{3} / \mathrm{s}$ & $<1.0 \mathrm{~cm}^{3} / \mathrm{s}$ \\
\hline HRR & $>500 \mathrm{MW}$ & $<500 \mathrm{MW}$ & $<50 \mathrm{MW}$ & $<5.0 \mathrm{MW}$ & $<0.50 \mathrm{MW}$ & $<50 \mathrm{~kW}$ & $<5.0 \mathrm{~kW}$ & $<0.5 \mathrm{~kW}$ & $<50 \mathrm{~W}$ \\
\hline \multirow{2}{*}{ Acc. mass: } & - & - & - & - & - & $<3.6 \mathrm{~kg} / \mathrm{h}$ & $<360 \mathrm{~g} / \mathrm{h}$ & $<36 \mathrm{~g} / \mathrm{h}$ & $<3.6 \mathrm{~g} / \mathrm{h}$ \\
\hline & - & - & - & - & - & $<32$ tons $/ \mathrm{y}$ & $<3.2$ tons $/ y$ & $<320 \mathrm{~kg} / \mathrm{y}$ & $<32 \mathrm{~kg} / \mathrm{y}$ \\
\hline
\end{tabular}

Figure 3. Suggested leak rate categories including safety related leaks and fugitive emissions. 
The heat release rates of the potentially ignited gas leaks, assuming a heat of combustion of about $50 \mathrm{~kJ} / \mathrm{g}$ [18] and 100\% combustion efficiency, are also included in Figure 3. This was done to increase the understanding of the dimensions of a fire if a leak should become ignited. The last lines of Figure 3 include leak rates in units of hours and years, as that is relevant for evaluating and reporting fugitive emissions for environmental impact.

It should be noted that whether a hydrocarbon gas leak may represent a fire and explosion hazard is very dependent on the ventilation conditions. In unventilated enclosures even minor leaks, when undetected, may result in hazardous concentrations in hours, days or weeks depending on the size of the enclosure. It is in the present work assumed that such leaks will be discovered by fixed point gas or line-of-sight detectors as the concentration reaches the $\mathrm{H}$ alarm level, for example, $10 \% \mathrm{LEL}$ or 1 LELm, respectively.

\subsection{Risk Evaluation Guide}

In order to repair a leak of for example, $5 \mathrm{~cm}^{3} / \mathrm{s}$, depressurization of a process module may be necessary. This would normally include flaring, which also releases hydrocarbons due to partly incomplete combustion. Depressurization to repair a leak and pressurization again after the repair and start-up of the involved module, may also result in new leaks. It is therefore necessary to evaluate whether the processes involved when repairing a leak could result in any associated negative consequences.

Leak rates may not be constant but may develop with time. Under certain circumstances, the leak rates may develop very fast. The risk associated with a leak should therefore not be assessed only based on the observed leak rate, as such. In a high-pressure system, a minor leak of for example, $1 \mathrm{~cm}^{3} / \mathrm{s}$ originating from a corrosion attacked pipe should get much more attention than a similar leak from for example, a valve stem cage gasket. An immediate depressurization would be a proper action when a situation involving a sudden loss of containment may be anticipated. The risk evaluation and proper actions regarding an identified leak should therefore include issues relevant to potential immediate or long-term leak rate development, negative consequences if a repair is undertaken and so forth. A guide for instant risk evaluation was therefore developed and tested in the present work, as presented in Figure 4. 


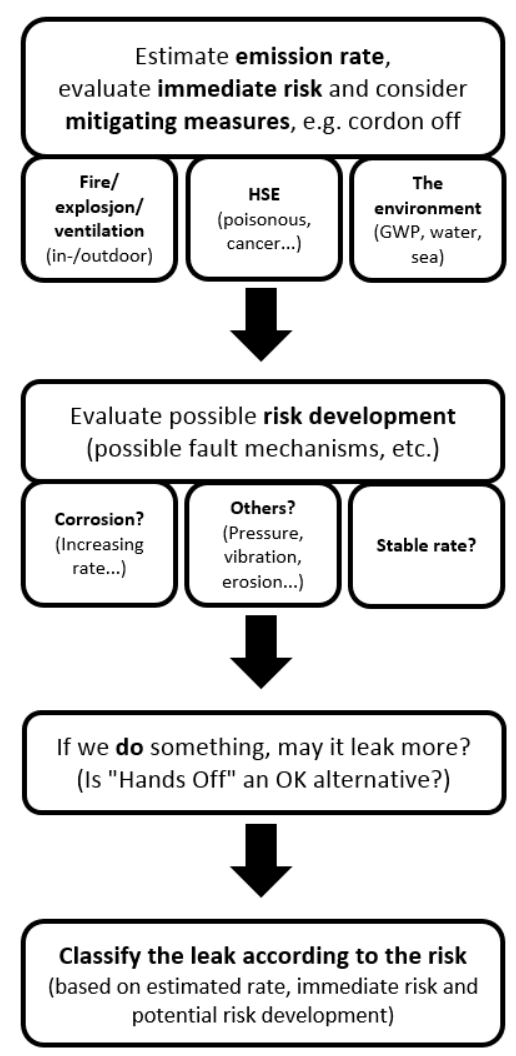

Figure 4. Sheet for simple minor leaks risk evaluation for prioritizing leak repairs.

\section{Experience with the Leak Categorization Concept and the Risk Evaluation Guide}

\subsection{Leak Detection Campaign}

The extended safety related leak rate concept was tested during leak detection campaigns at five onshore production facilities in Norway, that is, an oil refinery, a gas processing plant, a compressor plant, a methanol production plant and an oil terminal. None of these facilities had previously been screened by OGI campaigns. The screening was done by a third-party (The Sniffers, Balen, Belgium) using OGI cameras (FLIR GFx320, FLIR, Wilsonville, OR, USA) for identifying leaks and a HI Flow Sampler (Bacharach, Inc., New Kensington, PA, USA) technique for measuring leak rates. It should be noted that only about $40 \%$ of the identified leaks were quantified. This was partly due to for example, inaccessibility, weather conditions or general time constraints. Five leaks were immediately reported as potential safety related to the plant operators who took the proper actions for handling these leaks, either the actions were to cordon off, to depressurize and repair or to stay "hands-off" for a period based on a risk evaluation as presented in Figure 4.

The facilities varied substantially in size, from the large refinery and gas plant to the medium size compressor plant and the methanol production plant and to the minor size oil terminal. All the facilities had been regularly surveyed by plant operators using hand-held sniffers. No extra sniffing campaigns were done prior to the OGI campaigns. The number of leaks identified was quite consistent with the size of the facilities, that is, 124, 73, 29, 14 and 11 respectively. The number of quantified leaks, arranged in accordance with the suggested categorization system, is presented in Figure 5. 


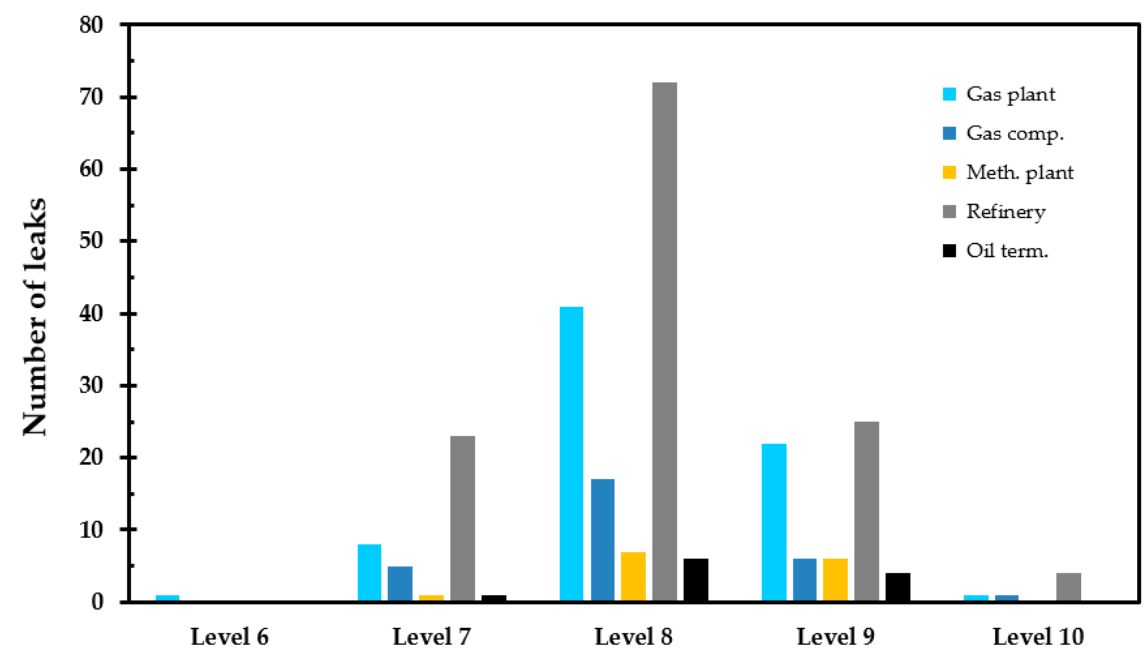

Figure 5. The number of leaks for each facility arranged per leak level.

The total accumulated leak rate from these 251 leaks was $0.73 \mathrm{~g} / \mathrm{s}(2.6 \mathrm{~kg} / \mathrm{h})$. If unattended for one year, this would result in loss of 49 tons to the atmosphere. It is seen from Figure 5 that leaks in Level 8 dominated the total number of leaks identified at all the facilities. However, when studying the leak rates in each category, as presented in Figure 6, a conspicuous single Level 6 leak at the gas production plant stands out as a major contributor. It is also seen that the leaks in Level 7 contribute much to the accumulated leak rate.

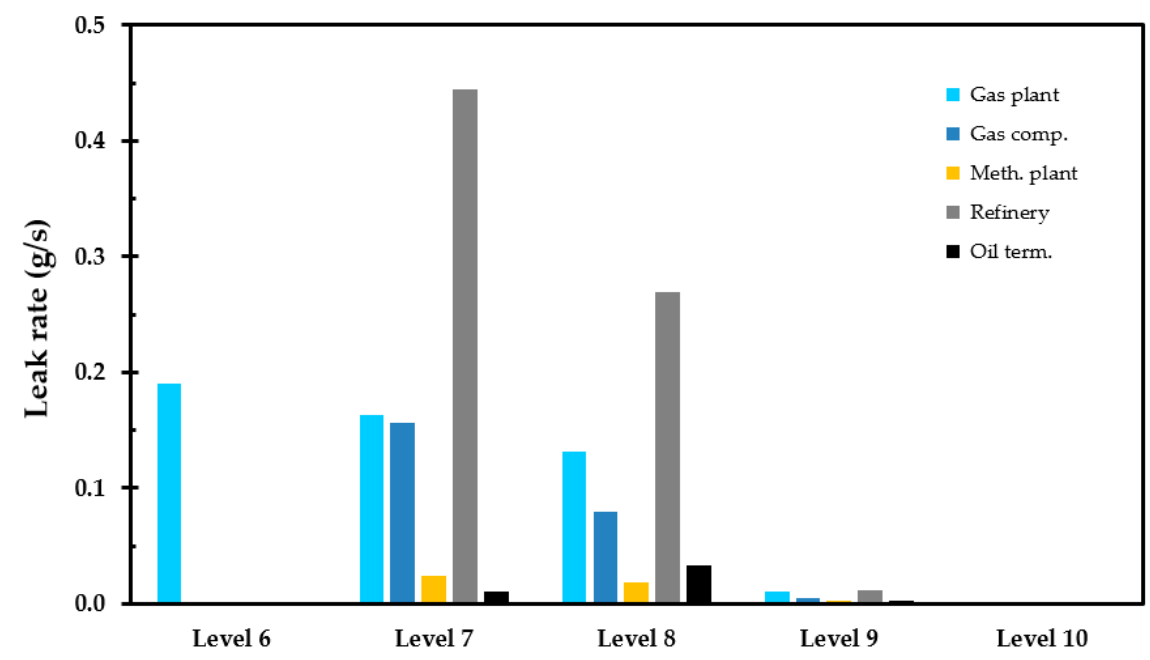

Figure 6. Leak rate for each facility arranged per leak level.

The distribution of quantified leaks from all the facilities combined, is presented in Figure 7. Though the Level 8 leaks dominate in numbers in Figure 7a, the leaks in Level 7 contributed most to the emission of hydrocarbons, as seen in Figure $7 \mathrm{~b}$, while the single leak in Level 6 contributed $12 \%$ to the accumulated leak rate. For both the gas processing plant and the gas compression facility, the leaking gas was mostly methane. 


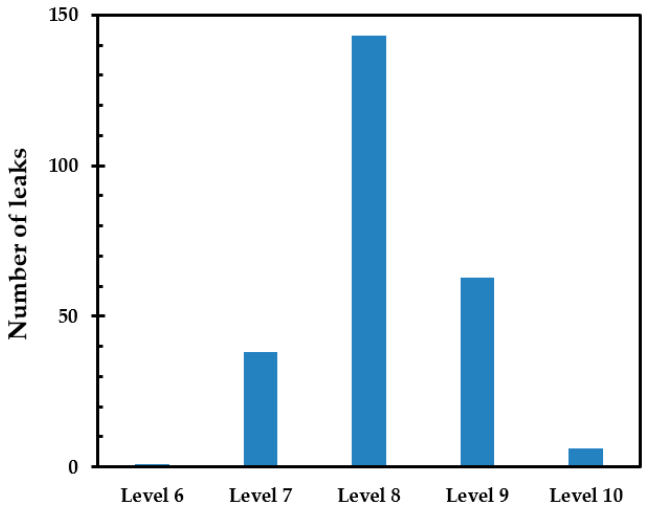

(a)

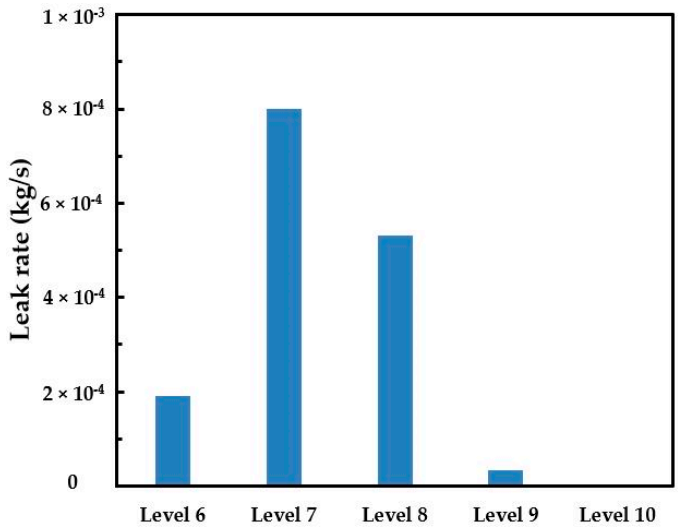

(b)

Figure 7. Number of leaks (a) and leak rate distribution (b) arranged according to the suggested categorization system.

The leak rates, arranged from the largest to the smallest leak, are presented in Figure $8 \mathrm{a}$ and the accumulated leak contribution is presented in Figure 8b. The largest of these 251 leaks. accounting for $12 \%$ of the total release rate, may then qualify for the label "super-emitter." The 21 largest leaks, that is, $8 \%$ of the leaks, accounted for $50 \%$ of the total release rate. The combined Level 6 and Level 7 leaks, that is, 39 leaks ( $15 \%$ of the leaks), accounted for $63 \%$ of the total emissions, as indicated in Figure 8 b.

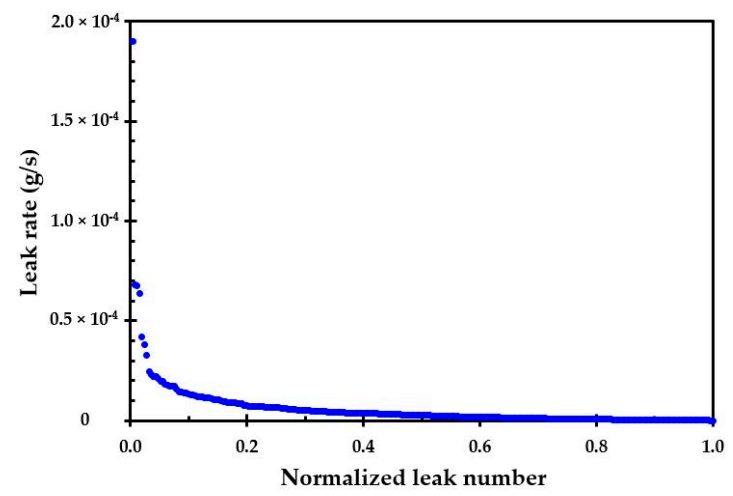

(a)

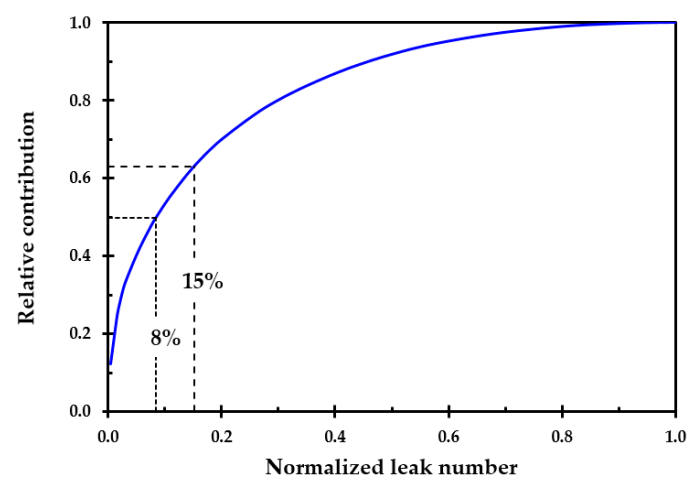

(b)

Figure 8. Leak rate (a) and accumulated leak rate (b) for the 251 quantified leaks arranged according to decreasing leak rate.

To be able to study the leak distribution for each plant in the same diagram, the leaks were arranged based on the leak rates, from large to small leaks. The leak number was normalized by the total number of leaks for each facility, as shown in Figure 9. For three of the facilities, that is, the gas compressor facility, the methanol plant and the oil terminal, a quite small number of leaks were identified and quantified. The results may, however, still indicate that there are some differences between the results from these facilities. The leaks detected for the methanol plant generally seem to be smaller than the leaks detected from the two other facilities. There also seem to be similar differences between the gas processing plant and the refinery. Except for 2-3 possible "super-emitters," the former generally exhibits lower leak rates than the latter. Since the same third-party surveyors did the leak search and leak quantification, this could possibly indicate some differences between the studied facilities. 


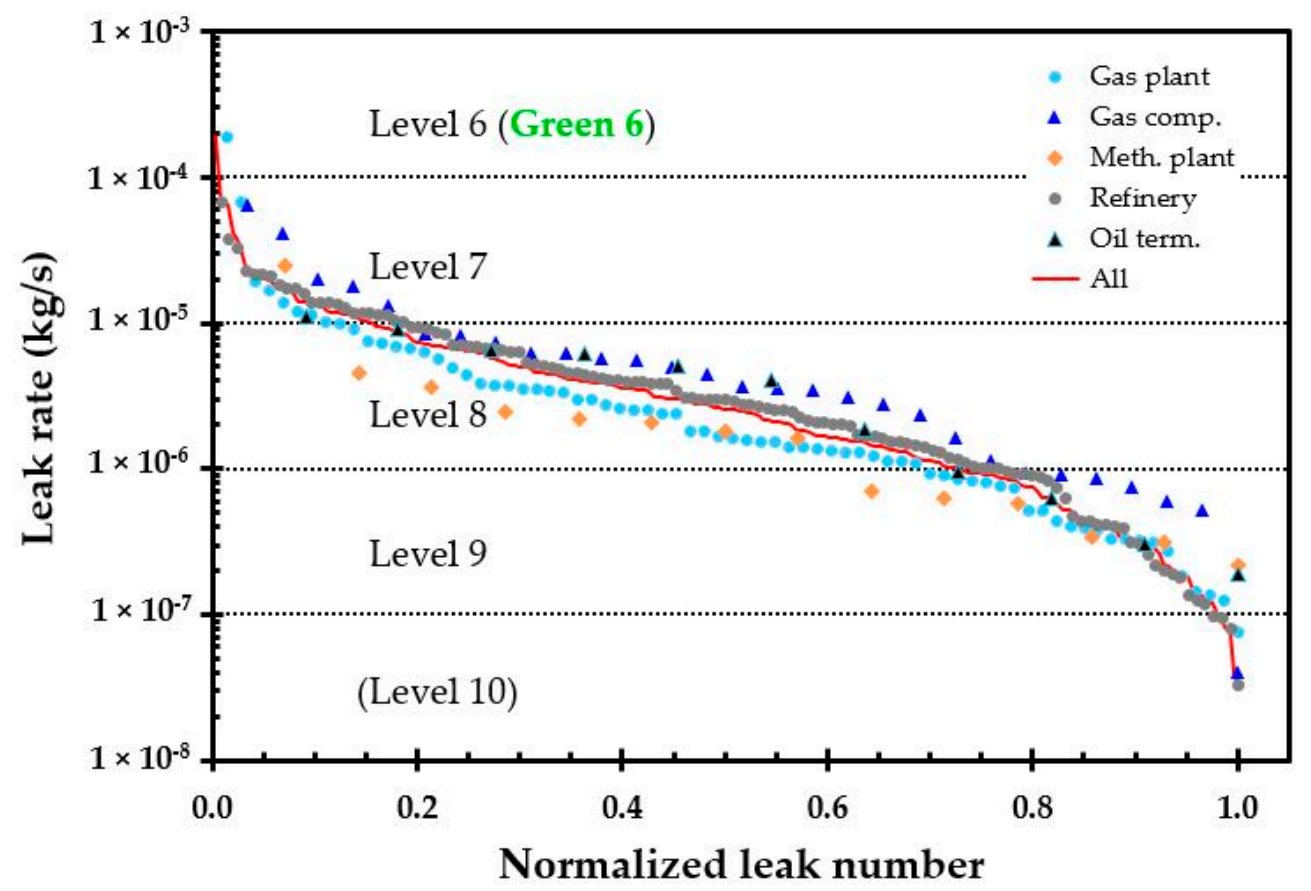

Figure 9. Leak rate for each individual quantified leak for the facilities, arranged per normalized number of leaks at each facility. The suggested leak categorization levels are indicated on the figure. The notion "All" refers to all the 251 quantified leaks, normalized accordingly.

It is generally known that the gas processing plant for several years has had a quite detailed fugitive emission leak detection program and has followed up their fugitive emissions in site maps and markings in the field. Historically, this facility had a higher number of known fugitive emission (FE) leaks on their FE map. The explanation for this could either be that this facility was leaking more than the other facilities or that it had a better leak detection program. This was also the case for the methanol production facility. An OGI campaign in more windy conditions could, however, mask the minor leaks and therefore skew the results in a diagram such as presented in Figure 9 towards higher emission rates since only the higher leak rates could then be detected. To draw any conclusion on this issue based on the OGI campaigns would therefore require information about the weather conditions during the OGI campaigns.

Very few of the detected leaks were in Level 10. This may to a large extent be explained by the difficulty to detect leaks at this level, that is, $<10^{-7} \mathrm{~kg} / \mathrm{s}\left(<0.1 \mathrm{~cm}^{3} / \mathrm{s}\right)$. Their contribution to the accumulated leak rate is also very small. Leaks in Level 9 are also generally quite difficult to detect. They do, as well, only to a minor extent contribute to the accumulated leak rate, as seen in Figure $7 \mathrm{~b}$. Since leaks in Level 9 and Level 10 are both difficult to detect and are observed to contribute little to the accumulated leak rate, it is suggested to combine these in the smallest practical level of leaks rates, that is, $<10^{-6} \mathrm{~kg} / \mathrm{s}$. In accordance to Figure 3, all leaks $<10^{-6} \mathrm{~kg} / \mathrm{s}$ are therefore suggested to be labelled as Level 9 leaks.

\subsection{Some Comments on the Obtained Results}

Rather than consuming much time for quantifying leaks in Level 9 (and Level 10), it may be worthwhile focusing more on the leaks that contribute most regarding environmental impact and safety related risk. Repair of leaks with rates in Level 7, Level 6 and so forth, should therefore be prioritized. When presenting the results from the leak detection campaign in figures like Figures 7 and 8 , it became quite clear that repairing the "super-emitters" should be focused. It therefore turned out to be an efficient way of communicating the OGI campaign results. 


\subsection{Leak Rate Diagram Guide}

For a few leaks, it was decided to monitor the possible development in leak rate over time using the bubble technique (CRC Leak Finder spray) and the diagram presented in Figure 2. This was based on an uncertainty whether the leak could gradually develop, that is, needed attention as suggested in the risk evaluation guide presented in Figure 4. It was then needed to give some information about the expected accuracy of such monitoring. It was, however, apparent that Figures 3 and 4 represented an aid in such risk evaluation processes.

\subsection{Benefits of OGI Campaigns Versus Regular Sniffing Campaigns}

The previous aspiration (sniffing) detection campaigns at the respective facilities were generally done at areas of the plant with easy access for the operators. Equipment associated with potentially leaking components had been given attention, while for example, possible leaks surfacing from cladding distant from a leaking component were not investigated. An important benefit of having an OGI camera survey was the possibility of detecting previously undetected leaks at places with limited or no access or where leaks were not expected.

Several of the detected leaks were at locations where quantification could not be done without erecting scaffolding. This limited the possibility for leak quantification by the Hi Flow sampler technique. However, from both an environmental and a technical safety point of view, detecting the gas leaks that required immediate action was important. Since some of these leaks could represent a hazard to the Hi Flow sampler operators, any work to quantify these leaks was off course deemed inappropriate. It may very well be that one or more of these leaks were larger than the accumulated rate found for the 251 leaks quantified.

\subsection{Leak Rate Risk Evaluations in the Field}

A plant operator always followed the third-party OGI inspector and the Hi Flow Sampler operator. The plant operators at the investigated facilities were well trained and knew the gases and liquids, as well as the process conditions (pressures and temperatures), in different modules at the facilities. Until now, the plant operators have, however, had little experience with the risks involved with leaks other than on an overarching level, for example, combustible gas or liquid products, liquids flashing when exposed to atmospheric pressure or self-ignition of hot oils when exposed to air, to name a few risks. When suggesting that plant operators should evaluate the risk related to a fugitive emission, for example, $5 \mathrm{~cm}^{3} / \mathrm{s}$ leak rate, they could not give any description of the associated risk beyond general terms, for example, it may ignite and cause a fire or an explosion. To relate the risk to something familiar seemed farfetched.

The presented risk evaluation guide, that is, as shown in Figure 4, was intended to assist in understanding the fire and explosion risk associated with a hydrocarbon gas leak. In Norway, most plant operators are familiar with the heat release rates of for example, a camping stove ( $2-4 \mathrm{~kW})$ and that a burning candlelight represents about 50-80 W. Using such familiar examples represented knowledge anchors for understanding that an ignited release rate in for example, Level 8 is between these two familiar heat release rates and that a release in for example, Level 5 is far more. Some operators even knew that a fully involved passenger car fire [28] would typically be representative for the heat release rates associated with level Green 4 . Adding the row of estimated heat release rate (HRR) of an ignited leak in the leak category table (Figure 3) clearly helped them to comprehend the risk associated with a potentially ignited hydrocarbon gas leak.

\section{Discussion}

In the present study, a simple guide for estimating volumetric leak rate for minor gas leaks was presented in Figure 2. The guide worked well when tested by plant operators. The results from such 
quantifications were intended for further risk evaluation, for example, monitoring development in the leak rate and so forth.

The consequence matrix for incidents and accidents in the Norwegian oil and gas industry was used as a template for categorizing safety related gas leaks and fugitive emissions. In line with the incident and accident consequence matrix, the suggested leak categories were arranged based on the leak rate in $\mathrm{kg} / \mathrm{s}$, in orders of magnitude in leak rate, descending to $<1 \times 10^{-6} \mathrm{~kg} / \mathrm{s}$. The suggested leak categories were used to analyse and present the results from third party OGI campaigns at five land-based facilities in Norway. The facilities comprised an oil refinery, a gas processing plant, a gas compression plant, a methanol production plant and an oil terminal. A total of 630 leaks were identified by the OGI campaigns. About $40 \%$ of these leaks, that is, 251 leaks, could be quantified by the HI Flow sampler technique. The number of quantified leaks at the mentioned facilities was respectively 124, 73, 29,14 and 11 with an accumulated leak rate of $0.73 \mathrm{~g} / \mathrm{s}(2.6 \mathrm{~kg} / \mathrm{h})$.

The reasons for $60 \%$ of the leaks identified by the OGI campaigns not being quantified were associated with limited access to the leaking components and weather conditions. It should be noted that five leaks were not quantified as it was considered unsafe for the HI Flow Sampler operator to approach these leaks, which were cordoned off for subsequent leak repair.

Leaks in Level $8\left(10^{-5} \mathrm{~kg} / \mathrm{s}, 10^{-6} \mathrm{~kg} / \mathrm{s}\right.$ ] dominated the number of quantified leaks. The single leak in Level $6\left(10^{-3} \mathrm{~kg} / \mathrm{s}, 10^{-4} \mathrm{~kg} / \mathrm{s}\right.$, that is, the largest leak quantified, contributed $12 \%$ to the accumulated leak rate. The leaks in Level $7\left(10^{-4} \mathrm{~kg} / \mathrm{s}, 10^{-5} \mathrm{~kg} / \mathrm{s}\right]$ together with the one leak in Level 6, contributed to $64 \%$ of the accumulated leak rate. The 21 largest leaks, that is, the $8 \%$ of the leaks, accounted for $50 \%$ of the accumulated leak rate.

Leaks not quantified were probably associated with leak rates similar to those quantified. The exceptions were the five leaks that could not be quantified due to safety reasons. These may have been much larger than the largest quantified leak. Some of these may therefore have been in Level 5 . If so, they would have dominated the accumulated leak rate. These leaks had not been detected by the regular sniffing campaigns at the facilities. Nor were they large enough or close enough, to be detected by the $10 \%$ (or $20 \%$ ) LEL H-alarm on point gas detectors or the 1 LELm H-alarm on the line of sight gas detectors. Without an OGI campaign at the facilities, these leaks could have continued leaking for years, with negative impacts on the environment and safety, as well as representing loss of valuable products. Getting these large leaks repaired was probably more important than all the rest of the leaks identified both regarding safety as well as environmental impact.

In the present study, it may be concluded that the OGI technology is a great tool for field use, as also concluded by Ravikumar et al. [21]. The best available OGI cameras are, however, quite expensive. When looking for "super-emitters," less expensive OGI technologies may be "good enough." Less costly cameras may also allow for using such equipment in organized training sessions and for demonstrating how the gases spread after larger or smaller releases [29,30].

The present study is limited to presenting the leaks according to their mass loss rates. Since the hydrocarbon gases have different GWP, the leak rates in $\mathrm{kg} / \mathrm{s}$ cannot be directly transformed to environmental impact. This could, however, in principle be done as each quantified leak originates from an equipment with known approximate gas composition. Rather than using resources for getting these details sorted for all the 251 leaks, one could introduce the approximate gas composition as a criterion for prioritizing repairs. A suggestion could be to multiply the leak rates with representative GWPs versus $\mathrm{CO}_{2}$ for the leaking gas mixture and prioritize according the respective leak's GWP. This would lead to a discussion of what factor to use [5] but would ensure that methane rich leaks got increased attention due to the high environmental impact of this gas.

The experience with the suggested classification system for fugitive emissions was quite good. It helped in getting the attention away from the large number of minor leak sources identified and focus on leak rates. This resulted in focus on the "super-emitters" contribution to the accumulated emissions. Acknowledging that a limited number of leaks accounted for a large proportion of the accumulated leaks may help addressing the "super-emitters" more frequently in the future. 
To directly view a leak in the OGI camera or subsequently on a recorded video, reveals much information about the leak. Since the plant operators know the leaking hydrocarbon gas from a given equipment, including, for example, the approximate average mole mass, operational pressure and temperature, the way the gas plume behaves can give much information even without any leak rate quantification. By occasional leak quantification by for example, soap screening (Leak Finder Spray) as a calibration of the visual information, the plant operators might be able to classify most leaks in the correct level in the suggested categorization table. Or, if the leak is large, classify it as a "super-emitter" for immediate attention. It is suggested that this is further investigated since and if this works, the focus can be shifted to early identify any "super-emitters" and thereby significantly reduce the accumulated leak rates, that is, reduce the environmental impacts and loss of valuable products.

The international focus on greenhouse gas emissions from the oil and gas industry is expected to be intensified to limit the global warming. This is especially important for production, transport as well as end consumers of products that may result in methane emissions [31-34]. The present study contributes to reduce the emissions at land based mid-stream facilities, where it is shown that identifying and repairing "super-emitters" would give a high benefit cost ratio. It seems quite clear to the authors that there must be good economy in identifying and repairing the "super-emitters."

\section{Conclusions}

The suggested system based on orders of magnitude in leak rates, from safety related leaks to the smallest fugitive emissions detectable by OGI camera, worked quite well. The simple risk guide sheet also worked well in assisting the operators during the risk evaluation process. The suggested categorization table was used for presenting and analysing detected leaks to help prioritizing repair of "super-emitters," which contributed most to the accumulated leak rates. A change in LDAR programs to coarser and more frequent OGI campaigns to earlier detect any new "super-emitter" is suggested. This would also improve the search for safety related leaks as well as prevent loss of valuable products.

Author Contributions: Conceptualization, T.L. and W.B.P.; methodology, T.L. and W.B.P.; field operations, T.L.; literature review, T.L. and W.B.P.; resources, T.L. and W.B.P.; data curation, T.L. and W.B.P.; writing-original draft preparation, T.L.; writing-review and editing, T.L. and W.B.P.; project administration, T.L.; funding acquisition, W.B.P.

Funding: The work related to organizing and presenting the study received no external funding.

Acknowledgments: The cooperation with Nick Mertens, Toon Van Nooten and Arno Tuerlinckx, The Sniffers Inc., Belgium, is much appreciated.

Conflicts of Interest: The authors declare no conflict of interest.

\section{References}

1. IEA. World Energy Outlook; International Energy Agency: Paris, France, 2018; Available online: www.iea.org/ weo2018/ (accessed on 15 May 2019).

2. IEA. Energy Efficiency Indicators: Fundamentals on Statistics. 2014. Available online: https://www.iea.org/ statistics/ (accessed on 22 January 2019).

3. Brandt, A.R.; Heath, G.A.; Cooley, D. Methane Leaks from Natural Gas Systems Follow Extreme Distributions. Environ. Sci. Technol. 2016, 50, 12512-12520. [CrossRef] [PubMed]

4. Stocker, T.F.; Qin, D.; Plattner, G.-K.; Alexander, L.V.; Allen, S.K.; Bindoff, N.L.; Bréon, F.-M.; Church, J.A.; Cubasch, U.; Emori, S.; et al. Technical Summary. In Climate Change 2013: The Physical Science Basis; Contribution of Working Group I to the Fifth Assessment Report of the Intergovernmental Panel on Climate Change; Stocker, T.F., Qin, D., Plattner, G.-K., Tignor, M., Allen, S.K., Boschung, J., Nauels, A., Xia, Y., Bex, V., Midgley, P.M., Eds.; Cambridge University Press: Cambridge, UK; New York, NY, USA, 2013; 222p, ISBN 978-92-9169-138-8.

5. Balcombe, P.; Speirs, J.F.; Brandon, N.P.; Hawkes, A.D. Methane emissions: Choosing the right climate metric and time horizon. Environ. Sci. Process. Impacts 2018, 20, 1323-1339. [CrossRef] [PubMed] 
6. Crow, D.J.G.; Balcombe, P.; Brandon, N.; Hawkes, A.D. Assessing the impact of future greenhouse gas emissions from natural gas production. Sci. Total Environ. 2019, 668, 1242-1258. [CrossRef] [PubMed]

7. Boothroyd, I.M.; Almond, S.; Worrall, F.; Davies, R.-K.; Davies, R.J. Assessing fugitive emissions of CH4 from high-pressure gas pipelines in the UK. Sci. Total Environ. 2018, 631-632, 1638-1648. [CrossRef] [PubMed]

8. Mandal, P.C.; Morshed, S.M. Localization of fugitive methane emission from natural gas distribution network of Titas Gas. Pol. J. Chem. Technol. 2017, 19, 127-131. [CrossRef]

9. Miller, S.M.; Michalak, A.M. Constraining sector-specific $\mathrm{CO} 2$ and $\mathrm{CH} 4$ emissions in the US. Atmos. Chem. Phys. 2017, 17, 3963-3985. [CrossRef]

10. IEA. World Energy Outlook; International Energy Agency: Paris, France, 2017; Available online: www.iea.org/ weo2017/ (accessed on 15 May 2019).

11. Alvarez, R.A.; Zavala-Araiza, D.; Lyon, D.R.; Allen, D.T.; Barkley, Z.R.; Brandt, A.R.; Davis, K.J.; Herndon, S.C.; Jacob, D.J.; Karion, A.; et al. Assessment of methane emissions from the U.S. oil and gas supply chain. Science 2018, 361, 186-188. [CrossRef]

12. Brandt, A.R.; Heath, G.A.; Kort, E.A.; O'Sullivan, F.; Petron, G.; Jordaan, S.M.; Tans, P.; Wilcox, J.; Gopstein, A.M.; Arent, D.; et al. Methane Leaks from North American Natural Gas Systems. Science 2014, 343, 733-735. [CrossRef]

13. Harriss, R.; Alvarez, R.A.; Lyon, D.; Zavala-Araiza, D.; Nelson, D.; Hamburg, S.P. Using Multi-Scale Measurements to Improve Methane Emission Estimates from Oil and Gas Operations in the Barnett Shale Region, Texas. Environ. Sci. Technol. 2015, 49, 7524-7526. [CrossRef]

14. Borda, E.S.; Korre, A.; Nie, Z.; Durucan, S. Comparative assessment of life cycle GHG emissions from European natural gas supply chains. In Proceedings of the 14th International Conference on Greenhouse Gas Control Technologies, GHGT-14, Melbourne, Australia, 21-25 October 2018.

15. Robinson, R.; Gardiner, T.; Innocenti, F.; Woods, P.; Coleman, M. Infrared differential absorption Lidar (DIAL) measurements of hydrocarbon emissions. J. Environ. Monit. 2011, 13, 2213-2220. [CrossRef]

16. Innocenti, F.; Robinson, R.; Gardiner, T.; Finlayson, A.; Connor, A. Differential Absorption Lidar (DIAL) Measurements of Landfill Methane Emissions. Remote. Sens. 2017, 9, 953. [CrossRef]

17. Ravikumar, A.P.; Wang, J.; McGuire, M.; Bell, C.S.; Zimmerle, D.; Brandt, A.R. "Good versus Good Enough?" Empirical Tests of Methane Leak Detection Sensitivity of a Commercial Infrared Camera. Environ. Sci. Technol. 2018, 52, 2368-2374. [CrossRef] [PubMed]

18. Drysdale, D. An Introduction to Fire Dynamics, 2nd ed.; John Wiley: New York, NY, USA, 1999; 476p, ISBN 0-471-97291-6.

19. Tutak, M.; Brodny, J. Analysis of the Impact of Auxiliary Ventilation Equipment on the Distribution and Concentration of Methane in the Tailgate. Energies 2018, 11, 3076. [CrossRef]

20. PSA. Regulations Relating to Management and the Duty to Provide Information in the Petroleum Activities and at Certain Onshore Facilities (The Management Regulations); Petroleum Safety Authority of Norway: Stavanger, Norway, 2017; 15p.

21. Ravikumar, A.P.; Wang, J.; Brandt, A.R. Are Optical Gas Imaging Technologies Effective For Methane Leak Detection? Environ. Sci. Technol. 2017, 51, 718-724. [CrossRef]

22. Log, T.; Pedersen, W.B.; Moumets, H. Optical Gas Imaging (OGI) as a Moderator for Interdisciplinary Cooperation, Reduced Emissions and Increased Safety. Energies 2019, 12, 1454. [CrossRef]

23. Watremez, X.; Marblé, A.; Baron, T.; Marcarian, X.; Dubucq, D.; Donnat, L.; Cazes, L.; Foucher, P.Y.; Danno, R.; Elie, D.; et al. Remote Sensing Technologies for Detecting, Visualizing and Quantifying Gas Leaks, Society of Petroleum Engineers. In Proceedings of the SPE International Conference and Exhibition on Health, Safety, Security, Environment, and Social Responsibility, SPE-190496-MS, Abu Dhabi, UAE, 16-18 April 2018. [CrossRef]

24. Gibson, G.; van Well, B.; Hodgkinson, J.; Pride, R.; Strzoda, R.; Murray, S.; Bishton, S.; Padgett, M. Imaging of methane gas using a scanning, open-path laser system. New J. Phys. 2006, 8, 26. [CrossRef]

25. van den Bossche, M.; Rose, N.T.; De Wekker, S.F.J. Potential of a low-cost gas sensor for atmospheric methane monitoring. Sens. Actuators B 2017, 238, 501-509. [CrossRef]

26. Eugster, W.; Kling, G.W. Performance of a low-cost methane sensor for ambient concentration measurements in preliminary studies. Atmos. Meas. Tech. 2012, 5, 1925-1934. [CrossRef] 
27. Dyakowska, E.; Pegielska, M. Comparison of the accuracy of two methods of methane fugitive emissions measurements-One according to EN 15446 standard and the other using the Hi Flow Sampler device-GERG (The European Gas Research Group) project results. Nafta Gaz 2016, 72, 660-665. [CrossRef]

28. Park, Y.; Ryu, J.; Ryou, H.S. Experimental Study on the Fire-Spreading Characteristics and Heat Release Rates of Burning Vehicles Using a Large-Scale Calorimeter. Energies 2019, 12, 1465. [CrossRef]

29. Metallinou, M.M. Liquefied Natural Gas as a New Hazard; Learning Processes in Norwegian Fire Brigades. Safety 2019, 5, 11. [CrossRef]

30. Log, T.; Moi, A.L. Ethanol and Methanol Burn Risks in the Home Environment. Int. J. Environ. Res. Public Health 2018, 15, 2379. [CrossRef] [PubMed]

31. Dalianis, G.; Nanaki, E.; Xydis, G.; Zervas, E. New Aspects to Greenhouse Gas Mitigation Policies for Low Carbon Cities. Energies 2016, 9, 128. [CrossRef]

32. Lin, H.-C.; Chen, G.-B.; Wu, F.-H.; Li, H.-Y.; Chao, Y.-C. An Experimental and Numerical Study on Supported Ultra-Lean Methane Combustion. Energies 2019, 12, 2168. [CrossRef]

33. Few, S.; Gambhir, A.; Napp, T.; Hawkes, A.; Mangeon, S.; Bernie, D.; Lowe, J. The Impact of Shale Gas on the Cost and Feasibility of Meeting Climate Targets-A Global Energy System Model Analysis and an Exploration of Uncertainties. Energies 2017, 10, 158. [CrossRef]

34. Balcombe, P.; Anderson, K.; Speirs, J.F.; Brandon, N.P.; Hawkes, A. The Natural Gas Supply Chain: The Importance of Methane and Carbon Dioxide Emissions. ACS Sust. Chem. Eng. 2017, 5, 3-20. [CrossRef]

(C) 2019 by the authors. Licensee MDPI, Basel, Switzerland. This article is an open access article distributed under the terms and conditions of the Creative Commons Attribution (CC BY) license (http://creativecommons.org/licenses/by/4.0/). 